\title{
Introduction
}

\section{Mary Gobbi}

Editor

doi: http://dx.doi.org/10.18543/tjhe-7(1)-2019pp13-15

The title of this present issue: 'Viewing Self: the impact of structural and personal critical reflection in a globalised world', offers both a literal and metaphorical anchor to this edition. First, the Journal itself is reviewed as we celebrate the achievements of Professor Luigi Filippo Dona dalle Rose (editor) and Dr Anna Serbati, (assistant editor) as their wise, patient and successful four years editorial guardianship of the Journal draws to a close. As I 'pick up the baton', it is timely for their reflections on this journey, as well as my emerging thoughts on the contemporary issues the Journal experiences in an ever -globalising world. As you will discover from Lupo and Anna's guest editorial, they have transitioned the Journal from the fledgling, carefully incubated and nurtured by Paul Ryan and the Journal founders, to the adult flying bird exploring new terrains and reaching an international audience beyond the boundaries of 'traditional Europe'. This has not been without its challenges as they cheerfully outline.

As the 'rookie' who picks up the baton, it is important to consolidate Lupo and Anna's work before discovering where to explore next. Then, together with our readers, contributors, estimable Editorial Board and the indefatigable managing editor Ladislas Bizimana Kayinamura, facilitate the Journal to soar over existing territory as well as reaching new destinations.

The theme of 'Viewing Self' is demonstrated in the four articles that form the bedrock of this edition. From a global perspective, one characteristic aspect of the Higher Education system of the United States of America is the use of significant donations to bolster or support the Institutions. In the paper Experience and enlightenment: "Customer-oriented" nine-stage major gifts management model of world-class U.S. universities, Lin et al. analyse the structural models of gift donation from a marketing perspective. They propose a nine-stage major gifts management model based on a case study of one major US university, analysis of theoretical models and international literature. As Lin et al., discuss, the major donors - be they charitable foundations, individuals or institutions- view themselves in particular ways associated with the nature of the donation. Similarly, the identity of the receiving institution is altered by the source of the donation, the type of 
donation and the facilities associated with it. Status, prestige, image, tradition and ranking are all associated with the giving and receiving of such major gifts.

Our next paper represents Higher Education change in a culturally different competitor to the US, namely Russia. This year, 2019, celebrated thirty years since the demise of the Berlin Wall and the emergence of sovereign states as a consequence of the breakup of the Soviet Union. It is appropriate therefore that our second article critically explores the journey of one subject specialism- the development of professional translators- within the Russian Higher Education system.

In a 'Competence-based approach to a module design for the Master Degree Programme in Translation: Challenge of Tuning Russia Tempus Project', Zabotkina et al., provide a practical example of national reform of a higher education framework. Their paper illustrates how the impact of globalisation and the evolution of the Russian Federation caused major reflection upon the traditional educational system and its value in a competitive environment. Hitherto, Russia, as part of the Soviet Union had sustained its own internal education system running parallel to, but not interfacing with, its European neighbours and its major competitor, the US. In this fascinating article, Zabotkina et al. situate the historical context with the drivers that influenced not only Russia, but also, due to the academic exposure with European neighbours, led to intellectual 'cross over' in this discipline. As both Russian and European researchers interacted, features from one tradition influenced the other. Challenges then arose concering different terminology, interpretation and practises of subject pedagogy. In other words, as the labour market required more professional translators, both Russia and Europe needed to address not only the competences in this field, but also the pedagogic strategies to achieve this, and the desirability of aligned educational systems.

In our third paper, the reflective lens turns to self-reflection on personal competence by the individual teacher in 'The autonomously watching of one's own video and its influence on the future biology teachers' professional vision' by Němečková and Pavlasová. The use of video as a pedagogic aid is more common now due to the lower costs, digital access and less intrusive nature of the video equipment. None the less, it is not without its challenges, including those of an ethical nature. Němečková and Pavlasová report a small sample case study use of video to enable trainee biology teachers to critically reflect upon their performance. The study was also interested in how this reflection informed the future practise and understanding of these novice teachers. Supported by mentors and written reflection, the authors 
found changes in the professional vision of their trainees following the use of the video reflection.

Our fourth and final paper takes us to the world of medical students and the development of reflective practice in Holder et al.'s Developing a Reflection Guiding Tool for Underperforming Medical Students: An Action Research Project. Reflective practice is a current expectation in many medical schools, particularly those influenced by the concepts of life -long learning and the professional necessity of critical review upon practice. In contrast, this paper demonstrates the tensions that can exist when the mainstream curriculum does not include embedded strategies to develop reflective practitioners. The paper reports how a reflective tool was employed to aid underperforming students, in the early stages of their medical education, when previous strategies had proved unsuccessful. This paper challenges us to realise that what may be accepted practise in one part of the globe is not in another. Hence, the applicability in different contexts requires analysis. Until proven otherwise, one is left wondering whether in different cultures and contexts, students of the same discipline respond in a similar fashion to various pedagogies. Similarly, the availability and concepts of student support and accessibility may be different as this study reveals.

In this issue, the metaphor of 'Viewing Self' at national, institutional and personal level has demonstrated how historical context, theoretical modelling, globalisation, competitiveness and the driver of professional aspiration, when subject to the critical lens of reflection, provide avenues for change and improvement within Higher Education.

So, once again 'thank you' to Lupo and Anna. It is my pleasure (and relief!) to know that their guiding hands will still play a key role for the Journal as they join the editorial board.

To our readers, please enjoy the literal and metaphorical reflections in this edition and remember, the Editorial Board warmly welcomes submission of articles that fall within the domain of this Journal. 


\section{Introduction}

\section{Mary Gobbi}

Editor

doi: http://dx.doi.org/10.18543/tjhe-7(1)-2019pp13-15

\section{Copyright}

Copyright for this article is retained by the Publisher. It is an Open Access material that is free for full online access, download, storage, distribution, and or reuse in any medium only for noncommercial purposes and in compliance with any applicable copyright legislation, without prior permission from the Publisher or the author(s). In any case, proper acknowledgement of the original publication source must be made and any changes to the original work must be indicated clearly and in a manner that does not suggest the author's and or Publisher's endorsement whatsoever. Any other use of its content in any medium or format, now known or developed in the future, requires prior written permission of the copyright holder. 